\title{
ASSESSING THE ENVIRONMENTAL CONDITION OF MINOR RIVERS IN URBAN AREAS
}

\author{
Vladimir Sergeevich Kuznetsov ${ }^{1}$, Denis Sergeevich Petrov ${ }^{1}$ \\ 1 Department of Geoecology, Saint-Petersburg Mining University, 21st Vasilevsky Ostrov, Line 2. 199106, Saint- \\ Petersburg, Russia. e-mail: vvvink2005@mail.ru
}

Received: 2017.07.07

Accepted: 2017.08 .20

Published: 2017.11.01

\begin{abstract}
This article is devoted to the study of water and sediment pollution in the channel of the Neva delta. Spectrophotometry was used to determine the concentration of pollutants in water. In the chemical analysis of the precipitate, atomic absorption spectroscopy and infrared spectroscopy were used. Analysis of the hydrochemical composition and sediment of the Smolenka River showed high concentrations of heavy metals and petroleum products. At the same time, the hydrochemical composition of the Smolenka River is highly unstable, but the concentration of oil products and lead in the sediments indicates the presence of local pollution sources. Based on our findings, we are guided by the restoration of the aquatic environment.
\end{abstract}

Keywords: sediment pollution, minor rivers, oil product pollution, environmental monitoring, heavy metal pollution

\section{INTRODUCTION}

The impact of human activity on water bodies has been a focus of research for over 100 years. Ever since the beginning of the scientific revolution, accompanied by increasing water pollution, it has been particularly important to study the qualitative properties of inland bodies of water.

To a significant degree, the environmental condition of water bodies depends on the scale of the transformation of the natural components of the drainage basin as a result of human activity. For this reason, particular attention should be paid to water ecosystems in areas with the strongest anthropic impact. This includes water ecosystems in populated areas [Malmqvist et al., 2002; Wu et al., 2015; Zhao et al., 2015]. A number of authors stress that in studies of the environmental condition of urban water bodies particular attention should be paid to heavy metal compounds, which can accumulate in various components of the water ecosystem and cause secondary pollution [Slukovskii, 2015; Valskys, 2015; Vosoogh, 2016].

The object of the present study is the river Smolenka, one of the minor rivers of St. Peters- burg and part of the Neva delta. The Smolenka starts as a distributary of the Malaya Neva; it crosses the Vasilyevsky District of the city and flows into the Gulf of Finland, separating Vasilyevsky Island from Dekabristov Island. Its approximate length is 3700 metres. The river course is fairly convoluted. In the 1960-70s, a canal was built that changed the course of the river. Since the Smolenka is a minor river in one of the most densely populated areas of Russia's second largest city, its environmental condition is a direct result of various anthropic factors. The most significant among them are the change of the river course, a large number of wastewater disposals, a considerable number of factories along the river, and heavy traffic along the river banks.

Considering the above, an assessment of the current environmental condition of this body of water is a task of obvious importance.

\section{METHOD}

The hydrochemical composition of the Smolenka is highly unstable, as attested by the chemi- 
cal analyses of its water carried out by students of St. Petersburg Mining University every summer. The chemical composition of the water samples is analysed by means of a LASA 100 mobile laboratory photometer, produced by Hach-Lange.

Samples are collected annually in early July at three locations. Location 1 is at the corner of Ulitsa Korablestroiteley and Novosmolenskaya Naberezhnaya; location 2 is at Liniya 16-17; location 3 is at Liniya 8-9 and the Uralsky Bridge (figure 1). The time interval between the sample collections at each location is one day.

At each location, 12 samples are collected and then analysed on site. All in all, 36 samples are collected and analysed every summer. The goal of the analyses is to measure the concentration of several metals, including nickel, lead, and copper.

As the data on the concentration of pollutants in the water painted a mixed picture, we conducted a chemical analysis of the river sediment. Unlike the water itself, where the concentration of the relevant chemicals varies over time and space, the sediment is an accumulating environment with a stable chemical composition. Moreover, the sediment can facilitate slower reactions that can create new, more toxic compounds [Fokin, 2010]. A review of the literature returned only general information on the level of the sediment pollution in the Smolenka [Fokin, 2010]; this information suggests that the sediment pollution in the river is likely to correspond to the levels "heavily polluted" and "dangerously polluted".

1. The sampling procedure followed the current standard practice in Russia [The state standard is 17.1.5.01, 1980; Ministry of NRE of the RF, decree No. 112, 2014]. In light of the sediment distribution and drift patterns, samples were collected at two locations. Location 1 (samples $1 \mathrm{a}$ and $1 \mathrm{~b}$ ) is $800 \mathrm{~m}$ from the start of the river, opposite the Kamsky Garden. Location 2 (samples $2 \mathrm{a}$ and $2 \mathrm{~b}$ ) is $1300 \mathrm{~m}$ further downstream, about $2 \mathrm{~km}$ upstream from the river's mouth.

2. The samples were prepared with two goals in mind: to identify metallic substances and to determine the total concentration of oil products.

The hydrochloric acid method and the nitric acid method were used in the sample preparation aimed at identifying metallic substances. The control sample was produced by adding bidistilled water: a 2-gram sediment sample was placed in a 100-millilitre flask, and 20 millilitres of bidistilled water was added to the flask. The mix was then stirred vigorously for 2 hours and left for 24 hours. The filtering was done through a $0.01-\mathrm{mm}$ filter. The control sample was used to produce a calibration curve based on the actual sample. The calibration curve was thus based onthe following

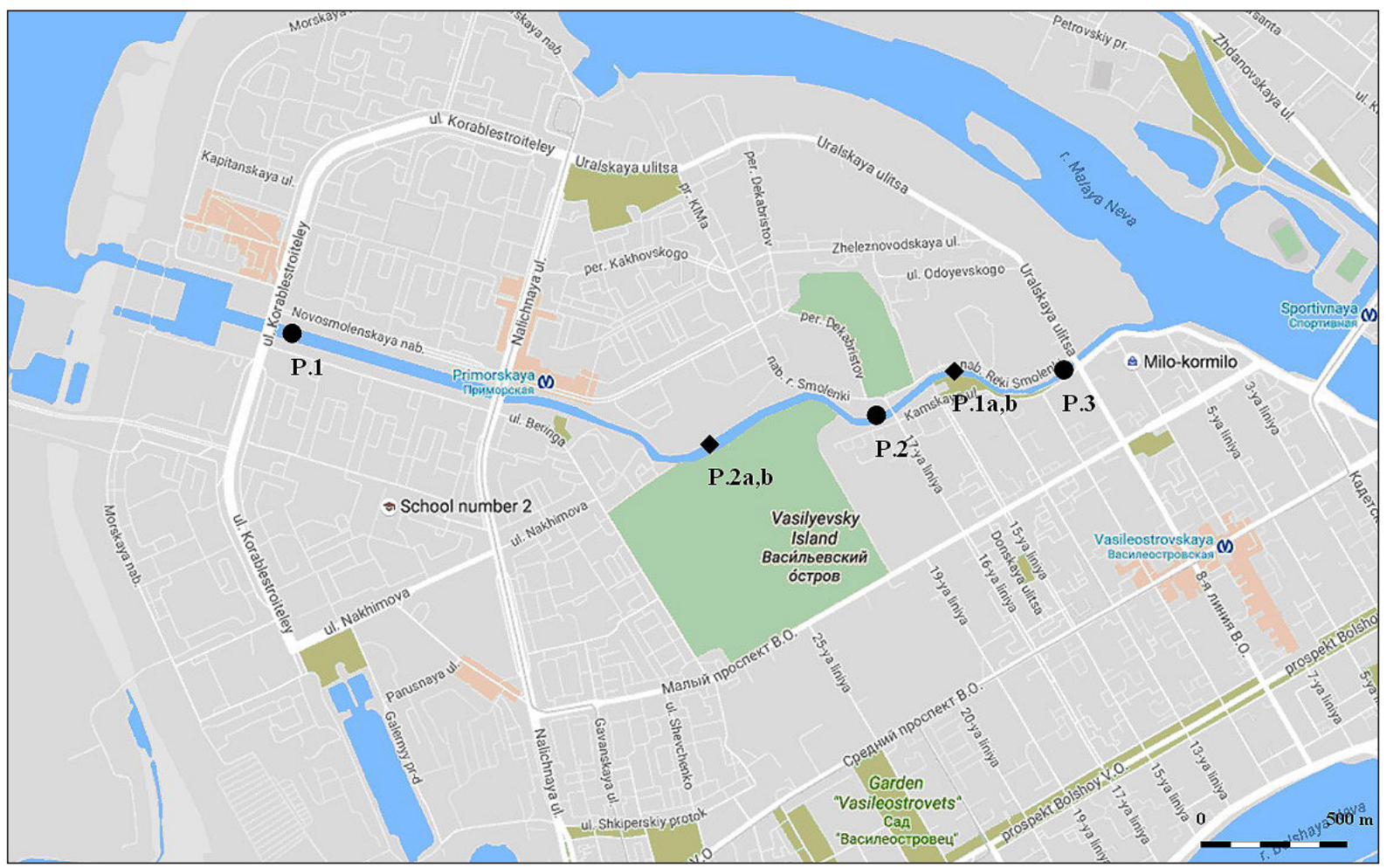

Figure 1. Water and sediment sampling locations (https://www.google.com/maps) 
samples: bidistilled water; $\mathrm{Fe}, \mathrm{Al}, \mathrm{Mn}, \mathrm{Cu}, \mathrm{Cd}$, $\mathrm{Ni}$, and $\mathrm{Pb}$ test solutions of various concentrations; the actual sample.

Two methods were used in the sample preparation aimed at extracting non-organic components (metals and amphoteric elements):

1. A 2-gram sediment sample was put in a 100-millilitre flask, and 20 millilitres of 0.1 $\mathrm{H}$ hydrochloric acid solution was added to the flask. The mix was stirred vigorously for 2 hours, then left for 24 hours and filtered.

2. A 2-gram sediment sample was put in a 100-millilitre flask, and 20 millilitres of $0.1 \mathrm{H}$ nitric acid solution was added to the flask. The mix was kept for 1 hour at $90^{\circ} \mathrm{C}$ without boiling and then filtered.

A KVANT-Z.ETA atomic absorption spectrometer was used in the study, in accordance with [The natural and normative document of the RF 16.1: 2.2: 2.3: 3.36-02, 2002; Guidance document 52.24.377-95, 1995]. The hydrochloric acid method showed the highest extraction rate for copper, cadmium, and nickel, while the nitric acid method showed the highest rate for iron, manganese, and lead. The measurement error is within the range of the method. The repeatability and replicability of the test conform to the specifications of the spectrometer.

Infrared spectroscopy was used to analyse and extract oil products, in accordance with
[Guidance document 5.22.07, 2005]. A 2-gram sample was mixed for 4 hours in a glass flask with 20 millilitres of hexane. The solution was then filtered; the filter was rinsed to remove the traces of extraction. Hexane was used as the test solution. When it was introduced to the working area, there were no air bubbles in the transparent volume of the solution.

\section{RESULTS AND DISCUSSION}

Table 1 shows the results of our analysis of 108 surface water samples collected in 2014-2016. As we can see, the concentration of the metals in each measurement is higher than the norm [Federal fishing agency of the RF. Decree No.10, 2010]. It is also worth noting that the concentration of pollutants in the river is unstable; even the averaged values show a 4-6-fold difference. The results of the chemical analysis of the sediment samples are shown in Table 2.

Assessing the pollution level of the sediment is difficult because the relevant Russian regulations for this environment lack the very concept of "maximum admissible concentration" [Fokin, 2010]. For the purpose of this study, we primarily used the recommended pollutant concentration values for standard sediments as the normal values (Table 3) [Norms and criteria for assessing

Table 1. The average concentration of the target substances in surface water samples from the river Smolenka in 2014-2016

\begin{tabular}{|c|c|c|c|c|c|c|c|c|c|c|}
\hline \multirow{2}{*}{$\begin{array}{c}\text { Component, } \\
\mathrm{mg} / \mathrm{l}\end{array}$} & \multicolumn{4}{|c|}{2014} & \multicolumn{4}{c|}{2015} & \multicolumn{3}{c|}{2016} & $\begin{array}{c}\text { Maximum } \\
\text { admissible } \\
\text { concentration, } \\
\mathrm{mg} / /\end{array}$ \\
\hline $\mathrm{Ni}$ & 0.020 & 0.035 & 0.029 & 0.035 & 0.098 & 0.033 & 0.045 & 0.021 & 0.017 & 0.01 \\
\hline $\mathrm{Pb}$ & 0.014 & 0.007 & 0.006 & 0.017 & 0.028 & 0.017 & 0.014 & 0.023 & 0.009 & 0.006 \\
\hline $\mathrm{Cu}$ & 0.029 & 0.035 & 0.039 & 0.019 & 0.024 & 0.041 & 0.006 & 0.008 & 0.015 & 0.001 \\
\hline
\end{tabular}

Table 2. The concentration of metals and oil products in the sediment samples

\begin{tabular}{|l|c|c|c|c|}
\hline \multirow{2}{*}{$\begin{array}{c}\text { Component, g/kg of dry weight; } \\
\text { (mg/kg for cadmium) }\end{array}$} & \multicolumn{4}{c|}{ Sample number } \\
\cline { 2 - 5 } & $1 \mathrm{a}$ & $1 \mathrm{~b}$ & $2 \mathrm{a}$ & $2 \mathrm{~b}$ \\
\hline Iron (Fe) & 44.0 & 43.2 & 37.0 & 36.7 \\
\hline Aluminium (Al) & 17.6 & 16.9 & 12.5 & 13.0 \\
\hline Manganese (Mn) & 28.0 & 29.0 & 23.5 & 24.0 \\
\hline Copper (Cu) & 7.2 & 7.0 & 6.3 & 6.4 \\
\hline Cadmium (Cd) & 4.5 & 4.9 & 12.0 & 12.6 \\
\hline Nickel (Ni) & 2.7 & 3.0 & 5.8 & 6.2 \\
\hline Lead (Pb) & 2.1 & 2.0 & 12.7 & 13.0 \\
\hline Oil products & 5.6 & 6.2 & 15.8 & 16.0 \\
\hline
\end{tabular}


Table 3. Pollution criteria for standard sediments

\begin{tabular}{|l|c|c|c|c|}
\hline \multicolumn{1}{|c|}{ Pollutant, mg/kg of dry weight } & Recommended level & Critical level & Control level & Intervention level \\
\hline Copper $(\mathrm{Cu})$ & 35 & 35 & 90 & 190 \\
\hline Cadmium $(\mathrm{Cd})$ & 0.8 & 2 & 7.5 & 12 \\
\hline Nickel $(\mathrm{Ni})$ & 35 & 35 & 45 & 210 \\
\hline Lead $\mathrm{Pb})$ & 85 & 530 & 530 & 530 \\
\hline Oil products & 180 & 1000 & 3000 & 5000 \\
\hline
\end{tabular}

the contamination of bottom sediments in water bodies of St. Petersburg, 1996].

On the whole, our assessment corresponds to the 1998 data. Each sediment sample should be classified as level 4: "dangerously polluted". Note the extremely high level of copper and nickel pollution (tens or hundreds of times higher than the recommended values at both locations), the high level of lead and oil product pollution at location 2 (25 and 16 times higher than the recommended values, respectively), and the cadmium concentration (2.4 times the recommended value at location 1 and 6.2 times at location 2).

Another indicator that can be used for an environmental assessment of the river sediment is the excess of the total forms of heavy metals compared to the maximum admissible concentrations (MAC) for soils [Hygienic standards 2.1.7.2041-06, 2006; Hygienic standards 2.1.7.2511-09, 2009]. The MAC for manganese is $1500 \mathrm{mg} / \mathrm{kg}$; the recommended concentrations are $130 \mathrm{mg} / \mathrm{kg}$ for lead, $132 \mathrm{mg} / \mathrm{kg}$ for copper, 2.0 $\mathrm{mg} / \mathrm{kg}$ for cadmium, and $80 \mathrm{mg} / \mathrm{kg}$ for nickel. The Clarke value for soils can be used as the target norm for iron and aluminium (38000 and 71300 $\mathrm{mg} / \mathrm{kg}$, respectively). Based on these values, we can note the following excess concentrations for the Smolenka: about 50 times for copper, 2.5-6.2 times for cadmium, 36-75 times for nickel, 16-99 times for lead, and 19-16 times for manganese. The iron concentration in the sediment is basically identical to the Clarke value; the aluminium concentration is 0.2 of the average figure for soil.

Finally, it is possible to assess the anthropic impact on a water ecosystem by comparing the results of the chemical analysis of the sediment with the background concentrations of the substances under study. A review of the literature returned the following background values for Neva sediments: $44 \mathrm{mg} / \mathrm{kg}$ for oil products, $17.2 \mathrm{mg} / \mathrm{kg}$ for copper, $9.64 \mathrm{mg} / \mathrm{kg}$ for nickel, $22.5 \mathrm{mg} / \mathrm{kg}$ for lead, and $50 \mathrm{mg} / \mathrm{kg}$ for manganese [Review of environmental pollution in the Russian Federation for 2005]. These values come from a study of the sediment at the start of the Neva in the Petrokrepost Bay. According to [Review of environmental pollution in the Russian Federation for 2005], the maximum iron concentration for the water complex comprising Lake Ladoga, the Neva and the Neva Bay was $8240 \mathrm{mg} / \mathrm{kg}$ (measured in the Volkhovsky Bay). We have not been able to find background values for the other elements. Compared to the background concentrations, we can note, on average, the following excess concentrations for the Smolenka: 400 times above the norm for copper, 520 times for manganese, 300-600 times for nickel, 90-570 times for lead, and 130-360 times for oil products. The iron concentration is, on average, 4.9 times higher than the figure for the Volkhovsky Bay.

\section{CONCLUSIONS}

We can draw the following conclusions from our empirical findings and the literature:

1. The hydrochemical composition of the river Smolenka is highly unstable, and it is characterised by a high degree of heavy metal pollution. Our analysis of the water has shown that the concentration of heavy metals is 3-24 times in excess of the norm. Our chemical analysis of the sediment pollution in the Smolenka, which is part of the Neva delta, has shown that it should be classified as class 4 pollution ("dangerously polluted"). The concentration of metals and oil products in the sediments is above the intervention level.

2. Our analysis of the sediment pollution in the Smolenka has identified three types of pollutants:

a) substances whose concentrations are hundreds of times above the admissible levels and background values along the entire river course (manganese, copper, and nickel);

b) substances whose concentrations are tens of times above the admissible levels and background values and increase towards the 
Smolenka's mouth (oil products and lead);

c) substances whose concentrations are several times above the admissible levels and background values (cadmium and iron).

3. The pollution level of the Smolenka's sediments requires a clean-up of the river. Besides other measures, sources of oil product pollution and lead pollution must be identified and eliminated.

\section{REFERENCES}

1. Federal fishing agency of the Russian Federation. (2010, January 18). On the approval of water quality standards for water objects of fishery use, including standards for maximum permissible concentrations of harmful substances in the waters of water objects for fishery purposes (Decree No. 10).

2. Fokin D., Frumin G., Rybalko A. (2010). Content and distribution of chemical elements in bottom sediments of the eastern part of the Gulf of Finland. Ecological chemistry, (19) 4, 236-242.

3. Federal Service for Hydrometeorology and Environmental Monitoring of the Russian Federation. (2006). Review of environmental pollution in the Russian Federation for 2005.

4. Hygienic standards 2.1.7.2041-06. The maximum permissible concentration (MPC) of chemicals in the soil.

5. Hygienic standards 2.1.7.2511-09. Approximate permissible concentration (ODC) of chemical substances in the soil.

6. The state standard is 17.1.5.01-80. Protection of Nature. Hydrosphere. General requirements for sampling bottom sediments of water bodies for analysis for contamination.

7. Malmqvist B., Rundle, S. (2002). Threats to the running water ecosystems of the world. Environmental Conservation, 29 (2), 134-153.

8. Ministry of Natural Resources and Environment of the Russian Federation. (24 February 2014). Methodical instructions for the implementation of the state monitoring water bodies in the part of organizing and conducting observations of the content of pollutants in the bottom sediments of water bodies. (Decree No. 112).
9. The natural and normative document of the Russian Federation 16.1: 2.2: 2.3: 3.36-02. Method for performing measurements of the total content of copper, cadmium, zinc, lead, nickel, manganese, cobalt and chromium in soils, bottom sediments and wastewater sediments and wastes by the method of flame atomic absorption spectrometry.

10. Guidance document 52.24.377-95. Method for performing measurements of the mass concentration of metals (Al, Ag, Be, Cd, Co, Cr, Cu, Fe, Mn, Mo, Ni, $\mathrm{Pb}, \mathrm{V}, \mathrm{Zn}$ ) in surface waters by atomic absorption with direct electrothermal atomization of samples.

11. Guidance document 5.22.07-2005. Soil quality. Method for performing measurements of the mass fraction of petroleum products in soils and bottom sediments by IR spectrometric method.

12. Slukovskii Z.I. (2015). Geoecological assessment of small rivers in the big industrial city based on the data on heavy metal content in bottom sediments. Russian Meteorology and Hydrology, 40 (6), 420-426.

13. Norms and criteria for assessing the contamination of bottom sediments in water bodies of St. Petersburg. Approved. Chief State Sanitary Doctor for St. Petersburg on (1996, June 17) and the Committee for Environmental Protection and Natural Resources of St. Petersburg and the Leningrad Region on (1996, June 22).

14. Valskys V., Valskiene R., Ignatavičius, G. (2015). Analysis and assessment of heavy metals concentrations in nemunas river bottom sediments at alytus city territory. Journal of Environmental Engineering and Landscape Management, 23 (2), 147-154.

15. Vosoogh A., Saeedi, M., Lak, R. (2016) River surface size fractioned sediments pollution with heavy metals (case study: Sefidroud river). Journal of Environmental Studies, 41 (4), 887-908.

16. Wu J., Stewart T.W., Thompson J.R., Kolka R.K., Franz K. J. (2015). Watershed features and stream water quality: Gaining insight through path analysis in a midwest urban landscape, U.S.A. Landscape and Urban Planning, 143, 219-229.

17. Zhao W., Zhu X., Sun X., Shu Y., Li Y. (2015). Water quality changes in response to urban expansion: Spatially varying relations and determinants. Environmental Science and Pollution Research, 22 (21), 16997-17011. 